\title{
Veterans' access to medication for opioid use disorders in Montana
}

JG Research \& Evaluation | Bozeman, MT 


\section{REPORT INFORMATION AND ACKNOWLEDGMENTS}

This report was written by Matthew R. Filteau, Kristal Jones, and Brandn Green of JG Research \& Evaluation.

The authors would like to thank all of the respondents who took the time to be interviewed for this report. Thank you as well to Joclynn Ware (AMDD SOR grant manager), Bobbi Perkins (Prevention Bureau Chief), and Ki-Ai McBride (Opioid Prevention Program Manager).

This study was funded by the Montana State Opioid Response (SOR) grant from the Substance Abuse and Mental Health Services Administration (SAMHSA), U.S. Department of Health and Human Services (HHS) to the Addictive and Mental Disorders Division (AMDD), Montana Department of Public Health and Human Services (DPHHS).

The study was reviewed by Western IRB and found to be exempt under 45 CFR $\S$ 46.104(d)(2).

The views and opinions expressed in this report are those of the authors and do not reflect the official policy or position of any agency of the government of the State of Montana.

This report was finalized in June of 2021.

\section{CITATIONS OF THIS PAPER}

Please use the following format when citing this paper:

Filteau, M. R., Jones, K. and Green, B. (2021). Veterans access to medication for opioid use disorders in Montana. JG Research and Evaluation. DOI: 10.36855/SOR2021.4. Available at: jgresearch.org/publications. 


\section{TABLE OF CONTENTS}

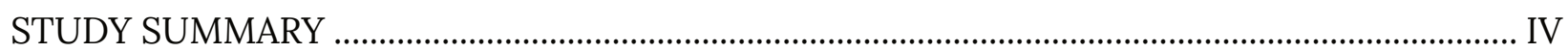

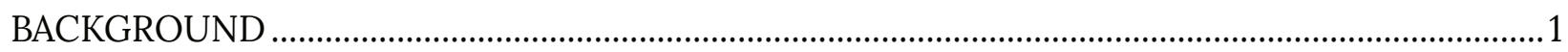

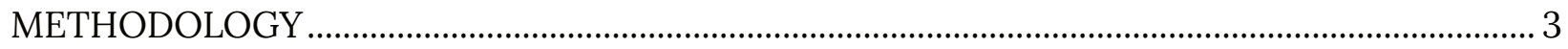

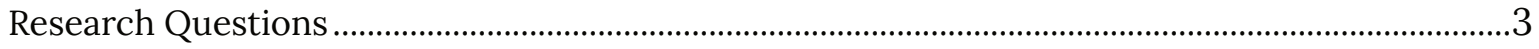

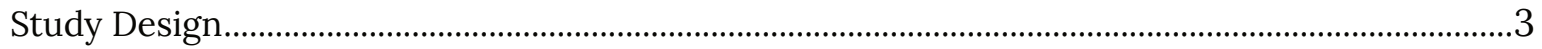

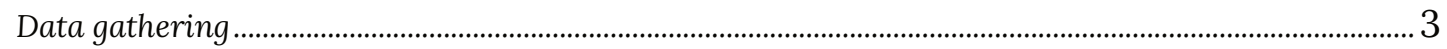

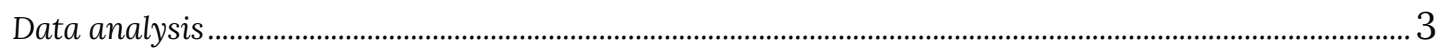

Limitations..........................................................................................................................................................

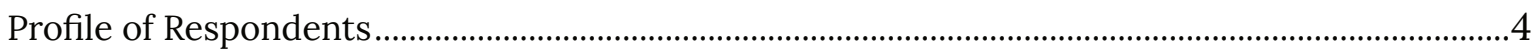

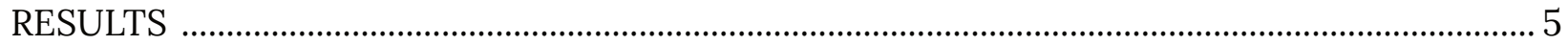

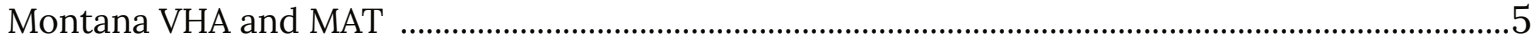

Demand for OUD Treatment within the VHA System ........................................................................ 6

Inpatient treatment demand ...............................................................................................................6

Outpatient treatment demand ………............................................................................................................7

Collaboration between the VA and Community-Based Organizations Serving Veterans ............. 9

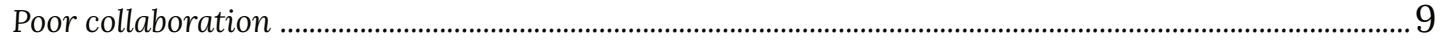

Good collaboration ........................................................................................................................................................10

Outreach and referral approaches taken by the VA .......................................................................................11

Wraparound services..........................................................................................................................12

Literacy among Veteran-Serving Organizations about SOR Sites .................................................13

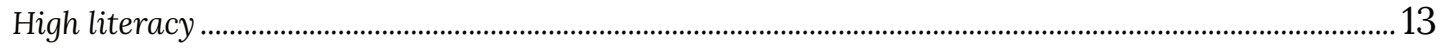

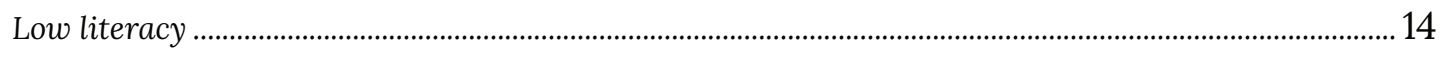

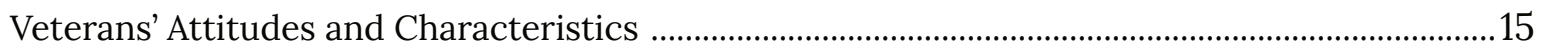

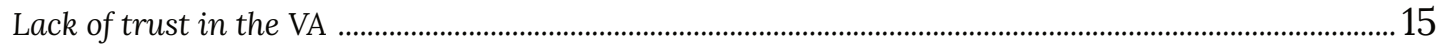

VA efforts to bolster trust ...................................................................................................................................

Opposition to the VA's model ......................................................................................................................17

Veterans' characteristics............................................................................................................................................ 18

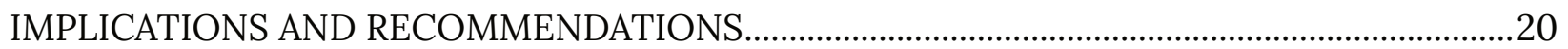

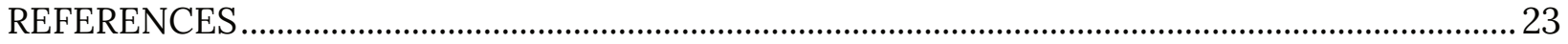

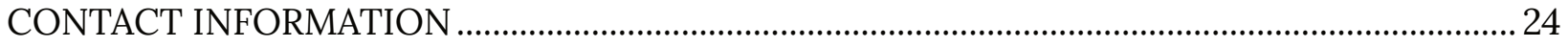




\section{STUDY SUMMARY}

Veterans have a higher rate of opioid use disorder (OUD) than the general population. The higher rate of OUD prevalence may contribute to an overdose rate twice the rate of nonveterans. In 2015 the Substance Abuse and Mental Health Services Administration (SAMHSA) labeled veterans a high-risk population for targeted engagement in the State Targeted Response (STR)/State Opioid Response (SOR) funding programs.

Montana is home to more than 70,000 veterans who are eligible for Veterans Health Administration (VHA) services. The MISSION Act provides the context within which SOR facilities can provide medication-assisted treatment (MAT) to veterans. Five SOR-funded sites report that they are non-VA medical community care providers with TriWest Healthcare Alliance (TriWest), which is the Veteran's Health Administration's third-party administrator (TPA).

An assessment of potential referral networks to SOR programs showed that VA behavioral healthcare staff and staff at community-based organizations serving veterans are relatively unfamiliar with SOR programs. Few participants knew that SOR programs existed, and even fewer knew that veterans could enroll. Professional staff more advanced in their careers and rank were the most familiar with the local SOR programs and the MAT services they offered.

Collaboration between staff at community-based organizations serving veterans and the VA seems tenuous. The Montana VA has instituted several programs and outreach activities to cultivate relationships among veterans, community organizations, and the VA; Montana Joining Community Forces is the most extensive such effort. Referrals to the Montana VA hospital's substance use disorder program (i.e., SUDs) largely derive from the justice system, primarily the veterans courts, which provide access to wraparound services. The SUDs program offers MAT with Suboxone, behavioral therapy, and more holistic approaches such as acupuncture, yoga, and other whole health methods.

Despite the VA's medical services and efforts to embrace the whole health model, many participants describe a lack of trust among veterans in the quality and expeditiousness of care provided by the VA. Furthermore, they believe that stoicism prevents many veterans from seeking VA services: asking for help is seen as a sign of weakness. These barriers raise risks for veterans, particularly with regard to overdose and suicide. To mitigate the lack of connection between the VA, veterans, and the general population, the VA engages in outreach efforts around the state aimed at bolstering trust and reducing stigma around mental health, suicide, and substance use disorders.

The demand for services among the veteran population and the lack of trust in the VA, coupled with the personalized care SOR programs offer, provide an opportunity for the Addictive and Mental Disorders Division (AMDD) to enhance collaboration with the VA. This collaboration would increase access to MAT, reduce the number of veterans at risk of opioid use disorder or with an untreated OUD, and decrease the overdose rate among veterans in Montana. 


\section{BACKGROUND}

The most recent national data suggests that roughly $11.7 \%$ of veterans suffer from OUD (SAMHSA, 2018; Vespa, 2020). After a significant increase in opioid prescriptions from VHA providers throughout the 2000s, the VHA launched the Opioid Safety Initiative to address over prescription and addiction ${ }^{1}$. At the same time, the VHA has been a leader in using medication-assisted treatment (MAT) for OUD, starting with methadone more than 30 years ago and implementing the use of naltrexone and buprenorphine starting in 2003 (Gordon et al., 2007). Furthermore, in 2014 the VHA began to distribute naloxone (Narcan), an opioid antagonist that is used in emergency overdose situations, to combat the rising death toll from opioid overdoses. However, according to a study of the VHA system, veterans continue to be twice as likely to die from accidental opioid overdoses as the general population (Bohnert at al., 2011).

As a response to the opioid crisis, including the disproportionate impact on veterans, the Substance Abuse and Mental Health Services Administration (SAMHSA) launched State Targeted Response (STR) /State Opioid Response (SOR) funding to support states as they work to address the opioid crisis. SAMHSA has reported significant decreases in prescription opioid misuse and use disorder between 2015 and 2018 as a result of these programs. Veterans were identified as a priority population within the STR and SOR programs, meaning OUD treatment need is high and/or access is disproportionately low.

Montana has more than 70,000 veterans eligible for VHA services and just three DATAwaivered practitioners within the state's VHA system, in Helena, Missoula, and Kalispell. In contrast, SOR sites are spread across the state. For many veterans, receiving MAT at SORfunded sites could greatly increase access to treatment. As of November 2020, however, fewer than $2 \%$ of patients at STR and SOR sites self-reported as being veterans. This report explores some of the reasons that admission rates for veterans to SOR-funded MAT remain low and includes recommendations for bolstering treatment for veterans at non-VHA locations.

To address the opioid epidemic, the VHA funded several national initiatives to increase access to medication assisted treatment for OUD. The Mission Act pertains to clinics outside the VA system ${ }^{2}$ and when trying to understand why SOR sites in Montana are not seeing and treating veterans for OUD, despite their designation as a high-risk population of concern, it is essential to first understand the MISSION Act and its role in enabling and constraining certain forms of care. The MISSION Act, Public Law No. 115-182, passed the US Congress and was signed into law in 2018, with the following purpose:

To establish a permanent community care program for veterans, to establish a commission for the purpose of making recommendations regarding the modernization or realignment of facilities of the Veterans Health Administration, to improve construction of the Department of Veterans Affairs, to make certain improvements in the laws administered by the Secretary of Veterans Affairs relating to the home loan program of the Department of Veterans Affairs, and for other purposes (VA MISSION Act, 2018).

${ }^{1}$ Information about the Opioid Safety Initiative can be found at US Department of Veterans Affairs (2020).

${ }^{2}$ Also see The Stepped Care for Opioid Use Disorder Train the Trainer (SCOUTT) Initiative-its primary goal is to "increase MOUD prescribing in VHA primary care, mental health, and pain clinics by training providers working in those settings on how to provide MAT and to facilitate implementation by providing an ongoing learning collaborative" (Gordon et al. 2020: 227). 
Veterans who qualify for VHA care are eligible to receive services from the Act's approved, non-Veteran Affairs (VA) medical "community care providers." There are six criteria that qualify a veteran for community care, and veterans need to meet only one of these criteria to be eligible:

1. Veteran needs a service not available at a VA medical facility

2. Veteran lives in a U.S. state or territory without a full-service VA medical facility

3. Veteran qualifies under the "grandfather" provision for eligibility based on distance to care from the former Veterans Choice Program (VCP)

4. VA cannot provide care within certain designated access standards

5. It is in the veteran's best medical interest

6. A VA service line does not meet certain quality standards

The first eligibility criterion likely impedes SOR facilities from serving veterans, since the VHA of Montana has a MAT program. In addition, based on self-reporting, more than half of the SOR treatment providers may not be "approved, non-VA medical community care providers."

The MISSION Act provides the context within which MAT program participation unfolds for veterans who have been honorably discharged. This study examines access to treatment within this context. 


\section{METHODOLOGY}

\section{Research Questions}

To better understand the experiences of veterans and engagement with MAT programs, we examine the following overarching research questions:

1. What factors enable and constrain veterans' access to MAT for OUD at SOR-funded locations?

2. How much do veteran referral networks know about OUD treatment options in and out of the VHA, and what are their perceptions of it?

3. How do barriers to and literacy about non-VHA MAT affect veterans' referrals to SOR-funded MAT programs?

\section{Study Design}

\section{Data gathering}

The primary means of data collection included in-depth interviews with community stakeholders, MAT practitioners at VHA facilities, and VHA employees familiar with OUD in Montana. Researchers contacted participants using a formal recruitment email and followed up by phone when necessary. When the respondent did not reply to any of these efforts, they were marked as "no response." Interviewers obtained verbal consent for the interview before proceeding with the interview process. Because of COVID-19, interviews were conducted over the phone with each participant's consent, audio recorded, and transcribed verbatim. All interviews were conducted confidentially, and all data in this report is reported anonymously.

Interviews were completed with individuals across the state of Montana who are familiar with veterans with OUD and who are in professional or informal roles that could allow them to direct veterans to a MAT provider funded by SOR. Types of respondents interviewed for this project are listed in Table 1.

\section{Data analysis}

The interview transcripts for this study were transcribed verbatim and analyzed in NVivo Qualitative Software (QSR International Pty Ltd., 2020). An iterative coding process was used. First, a deductive coding guide was created by two researchers familiar with the themes raised during the interviews. The researchers then expanded the coding guide to encompass more specific details and patterns. Each transcript was coded for overarching themes within each respondent category.

\section{Limitations}

The main limitation of this study is the difficulty of recruiting veterans who were not also staff within social services or social organizations. However, when the names of two veterans were referred to us, we did reach out and interview them. It was difficult to identify veterans who would have a perspective on barriers and access to SOR-funded MAT programs, since so few have been enrolled over the course of the STR and SOR funding cycles. Because the study is focused on referral barriers facing veterans, we focused on understanding the perspectives of professionals who could potentially be referral sources for veterans with OUD. 


\section{Profile of Respondents}

Researchers interviewed a total of 38 respondents in 30 interviews broken down within each category in Table 1 . Ten of the individuals self-identified as veterans but were speaking from their current professional role and thus were classified by that role.

\section{Table 1. Respondent types}

\begin{tabular}{llc}
\multicolumn{1}{c}{ Respondent category } & \multicolumn{1}{c}{$\begin{array}{c}\text { Types of respondents } \\
\text { Veterans Health Administration }\end{array}$} & $\begin{array}{c}\text { Number of } \\
\text { respondents }\end{array}$ \\
\hline $\begin{array}{l}\text { Social services and community-based } \\
\text { organizations }\end{array}$ & $\begin{array}{l}\text { Community care program } \\
\text { Homeless veteran homes } \\
\text { Veteran services in higher education } \\
\text { Social workers } \\
\text { Veteran drug courts } \\
\text { Veteran prerelease services }\end{array}$ \\
\hline Addiction treatment and support & $\begin{array}{l}\text { Behavioral health providers and executives } \\
\text { services }\end{array}$ & 22 \\
\hline Social organizations & AA and NA directors & \\
& VFW & 5 \\
\hline Politicians & American Legion \\
Veterans & Wounded Warriors projects & 2 \\
\hline
\end{tabular}

Note: $A A=$ Alcoholics Anonymous. NA $=$ Narcotics Anonymous. VFW $=$ Veterans of Foreign Wars. 


\section{RESULTS}

\section{Montana VHA and MAT}

The Montana VHA has a residential substance use disorder treatment program (known as SUDs) in Helena. There are three Suboxone providers statewide: at the VA hospital at Fort Harrison and at two of the VHA's community-based outpatient clinics (CBOCs) in Missoula and Kalispell. The SUDs outpatient program largely provides telehealth services to veterans. When interviewed, one behavioral health team member at the Montana VHA SUDs program succinctly clarified why SOR facilities were not seeing a higher number of veterans for treatment:

Because they get it at the CBOC facilities and the VA [in Helena]. So, I mean, there's no point in sending them out [in the community]. And, also, I think that some of those facilities won't fill out paperwork to work with the VA [to be an approved, non-VA medical community care provider]. You have to get into a contract to work for the VA or for the VA to send people to you, and [private/ state providers] have chosen not to do that. (MT VHA Behavioral Health Leadership)

This participant alludes to the first criterion of the MISSION Act, which states that since MAT services are available through the VA and their CBOC facilities, veterans cannot necessarily seek out non-VA treatment. Another behavioral health staff member at the VA referenced why veterans do not seek care in the community: "I would say we try to keep as many within the VA system as we can just because we know veterans, that's our population. We know how to treat them. We know how to treat them effectively. We like to keep the veterans here." Both participants mention that the VA provides MAT services, and the second states that the VA provides care to veterans instead of referring them to providers in the community.

We asked leadership within the Montana VA's behavioral health team to describe their SUDs program and also weigh in on why SOR practitioners throughout the state report so few veterans in their programs. One executive states:
We have the main facility and hospital in Fort Harrison, Montana, and then we have 14 clinics across the state. We have mental health or substance abuse staff in eight of those clinics, but we do telehealth services to the rest of those facilities. We have outpatient substance abuse treatment at most of our larger clinics-so, Billings, Bozeman, Great Falls, Helena, Missoula, and Kalispell. We have opioid replacement treatment through Suboxone. Currently we have three providers that are actively prescribing. All methadone treatment is done through contract-we don't have any methadone treatment at our facility. We also have a 24-bed residential unit at our treatment facility in Fort Harrison. And 12 beds are for PTSD and 12 beds are for substance abuse treatment. So especially when you look at substance abuse treatment at the VA, the goal would be that we try to provide those services in house if we can. Then we look at getting care in the community. (MT VHA Behavioral Health Leadership)

The preference to enroll veterans within the VA's SUDs program and treat them internally as a first course of action and then refer out, if need be, explains why SOR facilities do not see many veterans. Participants within the VA cited their literacy in veterans' health and their confidence in being able to provide the care and services that best enable veterans to recover. One key informant on the VA's behavioral health team was more than willing to discuss collaborating with AMDD. He states: "I am happy to talk with them and see what we can do. I am always looking at ways we can best meet the needs of veterans. We'd love to do it all in-house, but when we can't we'd love to partner." Members of the behavioral health 
team also spoke to the diversity of services offered by the VHA's SUDs program. One member of the behavioral health leadership team described the services available:

I would say from an opioid standpoint that this is a big issue in the VA. We have a lot of veterans who received a lot of opioids for a lot of years due to pain or other causes from their service in the military. And it used to feel like it was the right treatment, but with current research, it's not, and there's been a huge push within the VA to get people off of opioids. We're trying to build up a true multidisciplinary pain program. So a lot of veterans who have gotten addicted to opioids was because of a pain issue initially, so we're trying to holistically look at that opioid, we're helping them to look at that issue that got them into that in the beginning. We do acupuncture, chiropractic, and reiki, and yoga, and really looking at the whole health model, instead of just Western medicine. The Montana VA is not nearly as far as a lot of the other VAs in this journey, but we are really looking at how we can expand to alternative medicine. (MT VHA Behavioral Health Leadership)

The Montana VHA's SUDs program offers many holistic options for substance use disorders, in addition to MAT with Suboxone. The multidisciplinary approach to treatment presents potential modes of collaboration for AMDD and SOR treatment programs.

\section{Demand for OUD Treatment within the VHA System}

\section{Inpatient treatment demand}

The first limitation to the services that the VA provides pertains to inpatient housing. The inpatient SUDs program at the Fort Harrison VA Hospital in Helena can serve only 24 patients at one time (currently 12 owing to COVID protocols), and these beds must serve the entire veteran population in the state of Montana. SUDs patients include those requiring treatment for any substance, including, but not limited to, opioids. One member of the behavioral health team at the VA describes the inpatient residential program offered at Fort Harrison:
So, we're a roof over their head, but we provide more structure and more boundaries to get them engaged in inpatient-type treatments that are all evidence-based, psychotherapy groups with the idea that they transition into an outpatient setting upon discharging. So, we provide them the structure that they may not have had previously, or a lot of times we get a lot of rural veterans. So, folks that are living out in the boonies who can't drive two-and-a-half hours to go to their outpatient treatment. So essentially, we just provide a pretty intensive inpatient treatment. Again, PTSD and substance use disorders. And we treat every type of substance use disorder. [Interviewer: And how many beds are there?] 24. 24 beds. I think we're meeting the demand. I mean, you could always increase the number of beds, right? And we're full most of the time. Right now with COVID, we're only running at 50\% capacity just because of spacing issues, but 24 beds are full all the time [in non-COVID time].[...] We usually have 12 patients who are here for substance abuse and 12 patients who are here for PTSD or co-occurring treatment. But we're always full. And again, we could in a perfect world have more beds, but that would require more staffing and we require a number of different things too. So, I think we do a pretty good job meeting the demands right now. (Director, Homeless Veterans Home)

This behavioral health professional notes that there are typically 12 beds at Fort Harrison dedicated to patients seeking inpatient substance use disorder treatment, and another 12 for patients with mental health treatment needs. Now, however, owing to the physical distancing required for COVID-19 prevention, only 6 beds are allocated to veterans suffering from substance use in the entire state of Montana. Montana's VA cannot meet the demand for inpatient and outpatient services within the state. A recent report from the VA found that 
the average occupancy rate for the inpatient SUDs beds at Fort Harrison is 90\%, with a median wait time of 30 days for a bed to open (U.S. Government Accountability Office, 2019). Right now, in order to meet the demand, Montana sends veterans to inpatient facilities in South Dakota, Wyoming, and Washington State. As two participants who work with veterans in veteran support organizations state:

I know that there are programs within the community that contract with the VA. I think part of the concern for me would be the cost. VA services would have no cost for the veteran, so they could make use of those services and maybe put them in an inpatient program in South Dakota-I've had people who were sent to a treatment program in South Dakota and said it was just amazing, and then I've had people sent somewhere else and said it was awful and they were homesick. Or in Sheridan, Wyoming, or Fort Harrison, but as far as using another addiction treatment facility, I would be concerned about the cost. One, the time in getting someone seen and treated, but I would be concerned about the cost of those residential programs. (Director, Veterans Services in Higher Education)

So mostly, the ones I know of are VA facilitated. So, whether it be at the VA facility here [Fort Harrison], or the one in Wyoming. I know that those are two longer-term inpatient treatment programs that veterans often get engaged in. But the problem is that we don't have a lot of access to mental health support. The answer always seems to be, send them to the hospital. Well, they have eight beds in the psychiatric unit at Saint Pete's [Helena]. And so, if those beds are full, then the veteran is essentially getting turned away. And then that is just a short-term fix. There's no long-term plan on how that veteran is going to stay connected to a mental health care provider for a longer term than a 48-hour stay at St. Pete's. And so, I guess that's the main issue that we have in this community, is what are the options for that? I mean, we essentially have two options, and it's the center for mental health, and then if they can't see you, and it's a mental health crisis, then you need to go to the hospital. But that's not a long-term plan for someone. (Director, Veterans Services in Higher Education)

When approved, non-VA community care providers do admit veterans, the high demand for services by non-veterans across the state can result in problems down the referral and payment eligibility pipeline. For example, we interviewed US Senate staffers who spoke on behalf of a US senator from Montana who coauthored the MISSION Act; they noted that "there are long waits in the community, someone's appointment might not get approved [from the VA]." This means that even if SOR facilities sign up for the community care program, they must work within the referral structure of the VA: if a veteran is referred to the SOR facility and the SOR program has a long waiting list for admission, the referral may expire before the veteran's appointment and s/he may lose their opportunity to receive services. The Senate staffers went on: "We don't have a lot of providers in Montana, and I think most providers will sign up [for the community care program], and if they do, the backlog exists outside the VA, in the community." This participant implies that Montana currently falls short on approved, non-VA community care providers necessary to meet the demand from VA referrals when SOR programs are also charged with satisfying the demand among the general population.

\section{Outpatient treatment demand}

In addition to the VA's shortage of inpatient capacity for substance use disorder treatment, a main limitation to the services that the VA can provide pertains to the three DATAwaivered practitioners within Montana's VA system. These providers largely offer telehealth services to veterans receiving Suboxone, and interview respondents suggest that the 
demand exceeds the services provided. For example, one member of Montana's VHA behavioral health leadership states:

There's been a lot of discussion within our leadership about trying to expand that program and trying to expand it into primary care. But I don't think that we completely meet the need-I don't have numbers off the top of my head, but [...] We have one provider in Kalispell, one in Missoula, and one in Helena, and the bulk of their work is done through video conferencing. I don't have numbers, but I would say there is probably a need. [...] Prescribing in general is an area that we struggle in having enough providers to do that. (MT VHA Behavioral Health Leadership)

With only three DATA-waivered providers, participants in this study describe long wait times between when potential patients present with addiction and when they receive treatment. One VA provider states:
People who present need help immediately, not next week or next month. I would love to have immediate access to services because next week you're back on the needle or dead. Let's just say on Monday a guy presents, [and I say] "Well, yeah, I have an opening on Thursday at 9:30." Do you honestly think he's going to say, "Oh, yeah, great, see you at 9:30 on Thursday?" No way, he's going to go back out and use. (MT VHA Behavioral Health Provider)

In this provider's experience, the inability to do prompt inductions limits the effectiveness of the VA's MAT program. When asked about the addiction services offered by the VA, every participant described the VA's care as exceptional; however, VA staff disagree about how easily and efficiently veterans gain access to that care. One member of the behavioral health leadership team says that 30 days is the standard wait time:

If somebody came in, and they wanted to see somebody, like, say, that day. We would meet with them. We have hours that we meet with people face to face. And, so, from 11 to 12 and 3 to 4, we will either call people or see them face to face and help them get connected to services. And then in that consult, we put in a referral to the doctor. What we do is within 30 days. So we get them connected within 30 days, which is a pretty small window, and it's not the expectation of the private sector, but here at the VA, we try to do the best service possible. (MT VHA Behavioral Health Leadership)

This participant states that the VA tries to initiate treatment within 30 days of when a veteran presents to staff and assumes this is better than the timeline veterans would experience in the private sector. The discord between some behavioral health leadership and providers pertains to the effectiveness of this timeline. One VA provider described the workload:

This is a good program, we're doing good work, but it could be better: we need easier access, Narcan distribution, and a walk-in clinic. We [the VA] are providing better care than anyone in the community, but access, access to care is the problem. Vets have a problem getting the care. Fifty percent of my clinic is vets with OUD, I have 80 patients total with OUD and substance use disorder. [Interviewer: How do you manage this demand?] I overbook whenever I can-I do whatever I can do to get people in, or we send them to the Fort. (MT VHA Behavioral Health Provider)

This participant describes being overwhelmed with the demand for addiction services, and instead of providing prompt care in house, the provider sends veterans to the "Fort"-that is, Fort Harrison VA Medical Center in Helena, a 300-mile drive away. In this provider's experience, this approach is the most effective way to ensure that veterans suffering with OUD receive care more quickly. When community services could complement the VA's 
spatial and temporal gaps in service, VA staff state that they do not know about them. When asked how AMDD could better collaborate with the VA, one provider stated:

The schedulers and the consult meeting folks [at the VA] need to be trained, and they need to know about those services in the community and state. I'm not aware of many community resources for OUD. I'm not even sure that the schedulers in my clinic know about the program in Polson. (MT VHA Behavioral Health Provider)

This provider is located at the CBOC in Kalispell-less than an hour's drive from the Polson SOR facility-and had been unaware of the services offered there. He had learned about Polson's SOR site after the interviewer briefed him on the project and listed all the SOR site locations in Montana. With little knowledge of SOR clinics among VA staff, and limited resources available at the VA, the wait times between when veterans present to MAT staff and when they are admitted to the VA's MAT program can be quite lengthy.

\title{
Collaboration between the VA and Community-Based Organizations Serving Veterans
}

Many staff at community-based organizations that serve veterans reported a tenuous relationship with the VA: they either lacked solid connections with VA staff members or struggled to access information that helped their clients outside the VA. There were examples of poor collaboration and good collaboration between these two parties, but most community organizations reported challenges.

\section{Poor collaboration}

The majority of staff at community organizations reported challenges when collaborating with staff at the VA and accessing valuable resources for their clientele. For example, when one case manager of homeless veterans was asked to discuss her relationship with the VA, she stated:

\begin{abstract}
So the VA can be a really intimidating place, right? When you come in it's, "This is veterans' services." It's its own respected but elite place that a lot of [...] I've talked to other people in the community that are not connected in veterans' services, but they are in a lot of other areas, and they've been really transparent with me in saying, "I'm scared. I want to help in veterans' services, but I don't know where to go. I don't know where to start." When I hear people saying that, it kind of validates how I've felt over the years trying to connect there, and then I can turn around and encourage them that I've gone through the same thing in trying to learn services. But as I've gotten connected out at the VA, there are incredible people out there who are passionate, and they have gradually just warmly welcomed me in where I feel completely comfortable now going out. And if I have a question, I know right where to go, and if I don't, I know who to go and ask where to go. (Social Worker)
\end{abstract}

The Montana VA's reputation may precede someone's experience with it and intimidate professionals trying to connect their clients to services. Further, the complexity and diversity of services offered can present challenges for professionals when they search for the right department. The previous participant implies that challenges with the VA may deter other professionals from taking on veterans as clients and offering services to them for fear of an inability to navigate the VA's array of services. Several health care executives in Montana confirmed this lack of communication and collaboration between the VA and local agencies. One member on the call stated:

Yeah, I'd have to agree with that. There's almost no communication between local agencies and the VA. Kind of go back to your question. I still want to kind 
of, not to beat a dead horse, but it's almost like it is an insurance issue. The ones that do not have benefits, they end up in our locations because we exist to serve Medicaid-type clientele. And so they may end up in the programs, and then they have access to getting inpatient, peer support, case management, all the things that we provide. But the insurance is a big stopper. If they do have benefits, they really don't get into the system; they just get into VA. (MT Behavioral Health Executive)

Ironically, the above quote and the following one highlight that veterans who have been dishonorably discharged, and are thus not eligible for VA benefits, might have better access to substance use treatment.

Interviewer: For those folks who are dishonorably discharged, they are relying on what?

\begin{abstract}
Participant: Well, the majority of the time they qualify for Medicaid. They're just like anybody else that walks in off the street, that's having a hard time. We find out through the treatment process that they're a veteran, and it doesn't really change the treatment we give. It's just a little more information on what's going on and more importantly for the mental health aspect of it. But the honorably discharged ones, like I said, kind of have to go through the VA system, and that's a different animal. (Medical Health Provider)
\end{abstract}

An estimated 30,000 Montana veterans are ineligible for VA inpatient and outpatient substance use disorder treatment options (because of a dishonorable or bad conduct discharge, because they had fewer than 24 months of active-duty service, or because they are Reserve or National Guard members who were not activated for federal active duty). Veterans not enrolled in the VA healthcare system are at the highest risk of suicide and just as likely, if not more likely, to be at risk of some type of substance use. Healthcare executives throughout the state and study participants at the VA note that veterans who are ineligible for healthcare benefits are a major area of concern. However, in the case of substance use treatment, and MAT in particular, these individuals are likely to have either Medicaid or private insurance, and their ineligibility for VA benefits puts them at an advantage when seeking care at an SOR site.

\title{
Good collaboration
}

Some participants with an extensive background working with veterans in Helena spoke highly of the VA Hospital and their collaboration efforts. One participant within corrections captures the cohesiveness she and her clients experience with services such as the Drive a Van (DAV):

The DAV van is great. They come out, they pick the guy up, they drive him out to the VA. They do their appointments, they drop them back off at our front door. So it's actually very good. Plus, we have all the services with the Vet to Vet and Vets of America and VOA [Volunteers of America]. And the community here, we have the Willis Cruse House [transitional housing for male veterans]. So we've had a few people go live at the Willis Cruse House after here for extra support. And so there's more services, easier. And the Fort Harrison here is actually pretty easy to work with. They respond very well to, "Did he show up? How's he doing?" They respond to that very well. They're actually very good. I've been very impressed. Everything really is pretty good. They have just about everything out there that we need. (Director, Homeless Veteran Home)

This participant references a network of services, such as the free DAV service for disabled veterans, in Helena that help him accomplish his job and serve the veterans with whom he works. Many of the collaborations this participant cites are other community organizations 
and national programs implemented in the community. This positive collaboration is likely facilitated by the dense network of VA services provided owing to the presence of Fort Harrison, a situation that exists only in Helena.

\title{
Outreach and referral approaches taken by the VA
}

Many participants at the VA acknowledged the need to bolster their collaboration efforts throughout the state with community organizations. The VA has instituted a number of programs and outreach activities to cultivate relationships with veterans across Montana and community-based organizations. One participant who works with Montana Joining Community Forces describes one such collaboration effort:

\begin{abstract}
The Montana Joining Committee Forces, we put on the annual community resource fair and veterans' Stand Down, which I don't know if you're familiar with veteran Stand Downs or not. [...] Basically, it's an opportunity for all the resources and services to come together in one area, once a year, one place. And then we encourage veterans and their families to come out and visit. We have vendors, and we set up tables, and we encourage veterans to come out and talk with representatives from each organization and get connected to different services that exist. And then we also make sure that they're fed, they have something to eat for the day. We've supplied them with clothing, access to energy assistance help, all those different kinds of services. And then we've even had a few homeless veterans who have visited the event and were able to get some secured housing and get enrolled in the VA healthcare system. So it's really just an opportunity for everyone who has an interest, or a vested interest in not only the community, but veterans, to come out and share their resource and get those folks connected into their programs. So, we do that once a year, and we generally have about 100 to 150 . I think last year we might've had 175 folks who come out, and come through the event and get access to some resource. (Director, Veterans Services in Higher Education)
\end{abstract}

The Montana Joining Community Forces annual event is a consortium of resources available to veterans. This is a valuable resource for veterans in the Helena area, but a participant from the VHA's behavioral health team referred to veterans living throughout rural Montana and the need to reach out to this underserved population.

I think that figuring out ways to get these folks who are living in rural middle of nowhere engaged in care and successfully engaged in care. I think that's the big question that you need to continue to ask people as you go throughout your research and whatnot is, "How can we do better at helping someone in Ekalaka?" That's the million-dollar question.(MT VHA Behavioral Health Staff)

The Montana VA relies largely on the national advertising campaign to inform veterans and community organizations about their efforts to combat substance use disorder. Most of the information, however, is distributed through word of mouth at community events and among veterans within military or veterans' service organizations.

The national VA puts out quite a bit of money in advertisements for treatment. We don't do a lot of advertising in Montana, as far as opioid use disorders. I think most of it is from word of mouth. We have the Vet Centers, we have our staff, we have quite a few outreach staff who usually go out to quite a few events. Well, we usually go out to quite a few events, but the face-to-face events have definitely been cut down this last year. So, it's usually word of mouth. I'm in regular contact with a lot of the military or veterans' service organizations and talk to them about resources, and also our congressional staff are also aware of the resources we have. (MT VHA Behavioral Health Leadership) 
By getting this word out, the SUDs program within Montana's VA hospital gets its referrals largely from the correctional system. One VA executive on the behavioral health team states: "Another place we get a lot of referrals from is our veterans courts. Across the state we have veterans courts in Billings, Bozeman, Great Falls, and Missoula. And they're in the process of starting one in Butte." Another VA staff member discussed the value of veterans courts:

So vet court, we have a vet court in Great Falls, and we have a great therapist up there. And so she provides care. She's probably group five times a week for that population. And what they do in the vet court is they have like wraparound services. So if somebody needs employment, they have somebody that helps them with that. If somebody is not accessing all the services they have, they have case management to help them access those things. So the idea is just to lift that veteran up so that they can be successful. And the average is over a hundred, 200 hours of care during the time that they're in that court system. The court takes misdemeanor folks or possibly felony DUIs, but they don't take any violent offenders or anything like that. And, usually, substance use is part of their crime or a part of why they're in the position that they're in. And they can be in that program for up to two years, but they have great, great results. So they're like 70 to $80 \%$. (Veterans Prerelease Staff)

Interviewees described the complementary wraparound services provided by the vet courts as integral to patients' success with the SUDs program. In fact, many described this referral system as an invaluable network for the SUDs program. The sources for these referrals, whether social events or drug courts, are channels that SOR-funded MAT programs can pursue to fill their patient rolls with veterans.

Many staff at community organizations serving veterans also discussed how challenging it is for most of these organizations to reach veterans to refer to the VA for healthcare. The age of veterans, the digital divide, and the rural geography of Montana were all identified as factors. Additionally, as we discuss later in the report, lack of trust in the VA acts as a barrier to recruiting veterans into the VA's healthcare programs. One liaison between veterans and the VA states:

It's very difficult to infiltrate the veteran population here if they're not engaged in the VA healthcare system, because we're such a rural state, it's hard to get the word out about other services and resources that are available to them. And a lot of them, because we have such a high concentration of older veterans, aren't necessarily tech savvy. So they're not going to be getting on Facebook or getting on these social media sites to obtain the information. So I think it's just difficult to get the communication out to them. (Social Worker)

\section{Wraparound services}

Most VA employees and individuals running community-based organizations that serve veterans throughout Montana also discussed a housing shortage and lack of support services for veterans. The new Southwest Montana Veterans Home in Butte, with a capacity of 60 veterans, will help Montana tackle the housing shortage facing veterans. Little is known, however, about how this will affect treatment for veterans suffering from substance use disorder, since the set of services offered in that home does not explicitly include substance use treatment. Several community-based organizations provide resources to veterans through federal and state grants. These organizations provide wraparound care unavailable through the VA. For example, one program manager at a transitional housing residence states:

${ }^{3}$ For more information on the home, slated to open in fall 2020, see Montana DPHHS (2020). 
I run the [Homeless Transitional] House. It's a 12-bed transitional home for homeless or at-risk veterans, men. The bedrooms are shared, so I only serve men. And of course, because they're homeless, you can mostly assume that there's some kind of addiction involved, and I have seen a lot of opiate addiction. But most guys I would say [stay] six to eight months, generally. Some of them just need help with claims. They've been anti-VA, anti-government, whatever, because they got pissed off when they got out of the service. But then they reach an age or they have a physical need or something where they need to file claims, and that process is usually six months at the least. So sometimes it's just that: helping them get into that system, get things filed, and then once they have the benefits coming in, where they can be self-sufficient, then they can transition back out [into the community]. (Director, Homeless Veterans Home)

The transitional home provides a safe place to sleep, case management, transportation to the VA for appointments, and, as the participant states, help with claims. After their stay at this transitional home, veterans move to housing options within the community such as private apartments or other private residences.

\section{Literacy among Veteran-Serving Organizations about SOR Sites}

It was difficult to determine why staff at some agencies and community-based organizations that serve veterans had a higher literacy than others about non-VA MAT programs, but the amount of time staff had lived and worked in the local area is one relevant factor. Generally, staff had a higher knowledge of SOR sites and services the longer they had worked in an area. We see literacy about SOR programs as an integral factor in whether or not someone refers their client to the program for care, especially for SOR sites that have been approved to be a provider through the TriWest.

\section{High literacy}

Among the few staff at agencies and community-based organizations who were well versed in non-VA community treatment, including SOR MAT programs, most were in Helena, and more advanced in their careers and rank. When asked, "If I came to you seeking help for my opioid addiction, what treatment programs would you refer me to?" one director of a nonprofit that houses homeless veterans in Helena stated:

Yeah, we would tell them and I wish they would go. [...] We would tell them there's Boyd Andrews, but they cost money. One thing, you have to be cleaned up in order to go, so it's difficult. You have to be clean off the drugs in order to go. So it's difficult. There's the Leo Pocha Clinic, it's a Native American clinic that works really well, if you're willing to go, but most of our vets just aren't willing to go get help. (Director, Homeless Veterans Home)

This respondent had a firm grasp of the resources in the community and an extensive background housing the veteran and general population. Interestingly, he alludes to resistance among veterans even if they are referred to treatment. Similar to the previous participant, one executive in corrections was familiar with treatment options in the community for veterans:

Okay. If you were a veteran that gets full benefits, I would definitely direct you to the VA. If you were a veteran that might not have the benefits, it might take a while for you to get benefits with different processes and finding the DD-214 and all that stuff, and getting that stuff squared away. So, if you might need more emergency assistance, I might refer you to a different place in the community, such as the Helena Indian Alliance or Boyd Andrews Community Services or PureView to get an evaluation. (VA Staff) 


\section{Low literacy}

Most staff at agencies and community-based organizations serving veterans in Montana were unaware of the treatment options outside the VA. In fact, this quote from a case manager who works with veterans suffering from substance use disorder on a daily basis encapsulates the knowledge of many staff in this study:

\section{Interviewer: How much do you know about OUD treatment?}

Participant: I don't. That's part of why I'm very interested in talking with you. (Case Manager)

In the course of the interview, we learned that many participants who work at communitybased organizations serving veterans knew little about OUD treatment options in their communities and chose to do the interview as a means to learn from the interviewer. In some instances, the interviewer broke the role of interviewer to educate staff at agencies and community-based organizations serving veterans because those staff insisted on learning about the resources available. For example, here is an exchange between the interviewer and the director of a nonprofit for veterans who also serves as a liaison for veterans at a state university:

Interviewer: In your community, the SOR-funded program is Leo Pocha: The Indian Health Alliance. And anybody can go there. They don't have to be Native American-only a small segment of their population, particularly in the MAT program, are Native American folks. And so that's your local SOR, which is State Opiate Response program.

Participant: Well, see, and that's what I mean. I'm with an organization that knows a lot about the resources here, and I didn't even know that existed. (Director, MT Veteran Services in Higher Education)

Some respondents worked at several veterans' organizations but were unaware of non-VA community resources available to veterans. One participant, who came highly recommended as a liaison between the VA and community resources, knew a lot about the VA SUDs program, but when asked about the resources available in Helena, he balked at the question.

\section{Interviewer: What is that residential treatment program?}

Participant: So there's the PTSD and the substance use disorder, SUDs, substance use disorder treatment program. Let's see, one of them is a cohort, so basically the session starts with a bunch of people, and the other one is just on an as-needed basis. I believe the SUDs is the cohort with other vets and then the PTSD program is the one that you can go in when somebody graduates basically. There's waiting lists for both of them. So those would be the [local] source and even for all of Montana, really. We have folks from all over the state that end up at the RRTP, Residential Rehabilitation and Treatment Program [at Fort Harrison].

Interviewer: Okay. Do you know of any others that just exist in the community for folks who aren't veterans?

Participant: I'm trying to think. No, I don't think there is another one in Helena, actually. (VA Staff)

In summary, staff working with veterans had little knowledge of SOR programs or other programs providing MAT in their communities. Many respondents, like the previous one, 
demonstrate little to no knowledge of SOR programs, even for the general population. Few knew that these programs exist, and even fewer knew that veterans could seek services there.

\section{Veterans' Attitudes and Characteristics}

\section{Lack of trust in the VA}

One sentiment that emerged in nearly all interviews with individuals who work at the VA and in community organizations serving veterans was that a lack of trust in the VA acts as a barrier to veterans seeking help. The director of a housing organization serving veterans states:

The veterans I work with generally don't want anything to do with the VA. They've been burned quite a bit. So we actually try to work with them here if we can, and they actually prefer to go to our local hospital for treatment of any type than go out to the Fort or the VA-because it takes so long. (Director, Homeless Veterans Home)

This participant expresses disappointment in the VA's ability to provide expedited care at the Veterans Hospital in Fort Harrison. The VA's policy of connecting veterans to care within 30 days, and questions surrounding the quality of that care, leads to a lack of trust in their services among some veterans and among staff at veterans-focused community organizations. The idea of trust was coupled with the idea of stoicism. For example, one liaison between the VA and veterans states: "Veterans typically do not want to reach out for help. They think it's a sign of weakness, and they're not apt to reach out themselves for the help." Many participants echoed these ideas: stoicism and a lack of trust prevent many veterans from seeking help.

\section{VA efforts to bolster trust}

We asked staff at the VA to expound upon efforts to combat the perceived mistrust of the VA. We asked, "How do we reach people who say, 'I don't go the VA,' 'I don't think VA has my best interest in mind, 'I hate the VA, 'I don't trust the VA'? What efforts does the VA take to keep them engaged in care?" One member of the VA behavioral health leadership team stated:

That's the question that we all ask continually. I think that the reality is, for at least mental health, once we get veterans into care in our mental health programs, they really like it, and they think we do good work and they're really helped. So the key is getting them in and really changing the messaging that is coming in nationally, that this veteran didn't get this service or this veteran fell through the cracks. As a whole, I would say the Montana VA does a great job of meeting the needs of the veterans. We do a ton of outreach, especially in mental health and suicide prevention. We have the first or second, depending upon the study that you look at, most veterans per capita that commit suicide. So we do a ton of efforts on this. In the past years we have a contract with both of the major universities where we do suicide prevention campaign during the football games. We sponsor one of the games for the military appreciation game with the [National] Guard. So we've really looked at the ways we can get to veterans that aren't through the traditional manners. Another thing that one of our suicide prevention coordinators started was, she also started going to gun shows and getting gun locks and giving information about VA services. So really just trying to get information out to those folks that we traditionally don't get to. We're always looking at ways to get to those veterans, because when we look at our suicide numbers in Montana, the majority of veterans, more than half of those veterans killing themselves are not engaged in VA services. So that's what keeps me up at night is trying to better reach those veterans that aren't engaged. 
And how do I change the message to "the VA is good, and we do have your best interest"? (VHA Behavioral Health Leadership)

This quote encapsulates the VA leadership's focus on reshaping the VA's image and reputation among skeptical veterans. Advertising at football games enables the VA to target a behavioral health campaign to veterans or those close to veterans who may fall through the cracks. The VA takes seriously the high suicide rates in Montana, and, as this participant notes, those not enrolled in the VA are at highest risk. The VA's focus on reducing the stigma associated with mental illness, suicide, and substance use disorders is an effort to bolster trust in the VA and in the services they provide.

Other participants believed that the VA could garner trust by better aligning care with veterans' situations and life experience. For example, this director of a community organization serving veterans commented on the mismatch in care that takes place:

With this whole opiate thing, when the VA decided that this was an epidemic or that there was a problem, they kind of just cut everybody off their opiates. And I'm not kidding. One guy was told, I was in his appointment with him, by his doctor, "Maybe you should try yoga." And where I agree with those methods, I think they're beneficial, you cannot tell a Vietnam veteran who's in the 70s that maybe he should try yoga after he's been addicted to this pill for 10 plus years. So they get desperate and then they're going to street drugs. [...] And the VA here was actually offering kind of the new age stuff. There's tai chi and there's yoga and they have a sweat lodge and that kind of stuff that, where it is beneficial, you kind of have to be from that era to appreciate it or even want to try it. (Social Worker)

This participant describes that veterans may feel like their best interest is not being taken into account if they are prescribed unconventional, unfamiliar or unexpected treatment methods. Holistic methods of treatment may not work for older veterans or veterans unwilling to embrace alternative medicine.

Along these lines, some veterans lack trust in the VA's approach because it is not tailored to individuals. We spoke with one veteran with years of experience seeking help for behavioral health care at the Montana VA. He expressed disappointment with the VA's approach:

I would say it's hit or miss. It just depends. I've had bad experiences, I've had good experiences, and I've had experiences I wish I could forget. Their behavioral health team over there. [...] I'm trying to think of how to put this politely and respectfully. I know they're trying to help. However, they don't see a person sitting in front of them. They see an appointment. [...] That's a feeling that I personally get as a veteran. I understand they have to detach themselves; they have to make sure that they're professional, but it's not personable at all. It's an appointment. That's it. (Honorably Discharged Veteran)

This veteran's quote suggests that the VA cannot comfortably meet the demand and offer personalized care that meets his standards. Feeling like "an appointment" rather than a person seeking help degraded this participant's experience at the VA. Other veterans who run social service organizations tailored to veterans with physical and behavioral health issues made similar comments:

One of the issues that has come up with me is how many appointments we get through the VA and how few positions we have actually treating them. And when you think of just a rapid conveyor belt of appointments coming through, I kind of think of the "I Love Lucy" episode, where she's trying to make the chocolates and can't keep up. You got to come up with another solution. One of the solutions that I think that they come up with when they're just overwhelmed like that is, we have answers solely in chemistry rather than really dealing with the human. (Non-attributed quote to protect anonymity) 
This participant echoes the previous veteran: the VA cannot keep up with the demand and as a result tries to solve behavioral health issues with pills rather than focusing on an individual's needs.

\title{
Opposition to the VA's model
}

Some participants see the VA's approach to OUD treatment as medical, even if alternative therapies are also made available, since treatment often includes MAT. In fact, one participant who ran a holistic treatment modality for veterans across the country but based in Montana denounced the VA's approach as harmful:

\begin{abstract}
But veterans don't really trust the VA, and they don't trust the government because of what they've already done. If the government thinks that veterans are not becoming completely aware that they're being drugged out of their mind and that the system has failed, is designed to fail basically and create more patients, just I would say from my world, there's a lot of vets that detest the programs that the VA has. I have so many guys come on Suboxone. That is not a success. That is a failure. Putting a human being on Suboxone is a failure. Why are we counting that as a success? It is just mindboggling. I took them off one drug and gave them another drug. Success. That is the most ridiculous thing I've ever heard in my entire life. I have a lot of guys coming in [here] on Suboxone, so I know a lot about it. I mean, I've seen guys, and every guy that's ever come here on Suboxone's left and never went back on it. [Interviewer: For good?] Yeah, because Suboxone is a disease and it's poisonous. It's bullshit that we're even counting that as a success. You can quote me on that. [...] I had a guy last year, he was on 11 psychiatric medications. He showed up here. He had been on those medications for almost six years, and they just kept piling them on and piling them on. He basically wanted to kill himself but just couldn't. He was such a zombie. When he came here and I watched that guy come off those meds, and I watched him take control of his life and lose 40 pounds in 41 days and go on to go home and get a job and take control of his life, you should, maybe if he would be willing, ask him what it means to be living or dead, because he's an expert, not you or me. (Non-attributed quote to protect anonymity)
\end{abstract}

This participant opposes the medical model of addiction as a disease and promotes abstinence-only treatment approaches. As a veteran himself, he expresses distrust in the VA's treatment approach, and even says that he advises his clients to disobey their doctors' orders. Interestingly, this participant, with no background in behavioral health, openly sows doubt in the VA's medical model approach, thus potentially increasing distrust of the VA among the veterans with whom he interacts. This distrust serves his organization and may also create more harm by steering veterans away from care that could benefit their health. This participant goes on:

They recently just released, the Department of Veterans Affairs, that one in six guys that attend the VA leave on some type of psychiatric or pain-based medication. One in six. [...] I had the opportunity to speak to some people in Capitol Hill, that the VA's first line of defense because of liability is medication. It is much more difficult to put a guy on whole food eating, get him training, meditating, get his body together, whether he's missing a limb or not, whatever, remove negative substances, which we already know what they are, get this guy to focus, get his body cleaned out, put him on a pathway to where he can help himself. But that takes time. That takes time. The easy thing to do is say, well, you've got high blood pressure, here, take these meds and keep eating Five Guys [burgers]. Because we create the perpetual patient. (Non-attributed quote to protect anonymity)

This participant's opposition to the medical model is based upon his beliefs; the respondent truly wants to benefit the health and well-being of veterans. His comments reflect a more 
general divide within the practice of addiction treatment about whether abstinence or harm reduction is the most effective treatment. Some veteran-serving organizations, as exemplified by the quotes in this section, take issue with the VA's medical model and harm reduction approach and have instead built behavioral health treatment programs based on more holistic modalities such as diet, exercise, and mindfulness. And as we document in previous sections, according to many VA staff and patients, the VA also includes many of these same holistic or alternative treatment modalities in their pain management and addiction treatment programs.

\section{Veterans" characteristics}

Behavioral health care workers face unique challenges as they strive to personalize care and meet the healthcare needs of veterans. One participant highlights the needs among veterans of active-duty service:
I just had a tremendous amount of exposure to what it means to be at war. It's a tremendous part of me. And so when I was honorably discharged at the end of 2009 , I saw some people that I had served with fighting demons. And I saw the struggles that a lot of service members had just with physical ailments, with depression issues, with what is sometimes too categorically described as PTSD, with all these things. Not just that, but just the struggle of moving from a service life to civilian life. To put it really simple, you have so many service members that are highly trained, that are part of a team, they have a tremendous sense of purpose. They know that their team has their back. They know that their team counts on them having their back, and you've got that just tremendous amount of meaningful work and a purpose in something, a part of a team. And coming out of that and getting a job as a greeter at Walmart, of course, you're going to get depressed. Where's the sense of importance, where's the sense of belonging, where's the sense of mission, where's the sense of team, the sense of community? All that stuff that was so much a part of your military career is gone. And of course that drives a lot of people into depression. (Non- attributed quote to protect anonymity)

The transition from active duty to civilian life presents veterans with increased social isolation and physical distancing, as well as a loss of identity and purpose that affects their mental health. This change in lifestyle presents many new complications, and more personalized care could start immediately when veterans are discharged or when they retire. One veteran who also works at a community organization serving veterans notes:

I won't speak for all the branches, but I know what I got when I retired. I got a six-day course called TAPs. Transition Assistance Program. And five of those six days was getting on USA Jobs to apply for jobs. That was it. And then one day was spent on, here's the benefits you have as a retiree, you can get education, you can get VA benefits, this, that, and the other. I did not have one class on coping with stress, life skills. Hey, here's what you can look forward to when you try to transition into normal society again, none of that is provided. So if I could change anything, it would be the way the military handles people transitioning out of their service. Again, I'm not bashing them. They are starting to do that now. Because of the last several years with PTSD getting such a spotlight on it nationwide, the military is picking up on that, and they're definitely getting better with those kinds of skill sets, helping people transition out. So it is improving. My magic wand would have been too bad you guys didn't do this years ago. (Veterans Prerelease Staff)

Veterans note that the transition to civilian life is a stressful, drastic change that can present vets with two options: (1) behavioral health care or (2) self-medication. If veterans were socialized to access and accept support from behavioral health programs upon release, it could cut down on some of the self-medication that occurs among the veteran population. 
One member of the behavioral health leadership team at the VA discusses the frequency of substance use disorders and provides reasons for why they occur:

I would say alcohol use disorders are number one, opiate use disorders are number two, and stimulants are number three. But again, that's variable based on demographics and where you're at in the state as well, as well as the different populations of veterans. [...] So I think a lot of times what you see with more of the older veteran population is self-medicating with more of the sedative-type substances. So more central nervous system, the presence. That being said, there is a number of them that do use stimulus still, but with the younger veterans, we're starting to see more and more stimulant use disorder because people get addicted to adrenaline and the adrenaline of war is [...] it can be highly addictive. And when they come home, everything is boring. And so what you'll see is they'll lean towards stimulants to repeat that adrenaline balloon that they had. So we do see increasing stimulant use amongst younger veterans. (MT VHA Behavioral Health Staff)

The age of veterans, their residential location, and their active-duty experience can affect their behavioral health and substance use upon leaving the military. The popularity of substances among the veteran population parallels substance use among the general population in Montana, with alcohol as most prevalent, followed by opioids and stimulants. In addition to the substances people use by age, staff at community organizations noted other differences over time. One participant reflected:

I think that what I've seen, it's such a change in the number of disabilities, the percentages of disabilities that these veterans are dealing with, that they're struggling with. Initially it was more Vietnam-era veterans that struggled with PTSD and mental health issues, abuse, but these younger veterans are so. [...] I mean their service was so difficult for most of them. I'm making a huge generalization there, but about two-thirds of our veterans have a rated disability. (Director, Veterans Services in Higher Education)

This participant's observation complements that of the participant in the previous section who opposes the VA's medical model: diagnoses of OUD are soaring in part because of the need for more pain medication to address physical injuries sustained during active duty. This participant addresses the issue not in opposition to the medical model and the diagnoses themselves, but rather from the perspective of how the experiences and needs of younger veterans differ markedly from those of older veterans. 


\section{IMPLICATIONS AND RECOMMENDATIONS}

The research questions driving this report focus on barriers to treatment both within and outside of the VHA for veterans with OUD. Implicit in those questions is a basic need to understand whether demand for OUD treatment exceeds the VHA's capacity to provide treatment in house and, if so, how to facilitate and encourage veterans to seek treatment at SOR-funded MAT sites. It is possible to estimate the supply-demand balance by noting that there are more 70,000 veterans eligible for VHA services in Montana and three DATAwaivered MAT practitioners to cover this population. If Montana veterans experience OUD at rates comparable to the national average among veterans (11.7\%), then roughly 8,000 veterans could require some type of OUD treatment (SAMHSA, 2018; Vespa, 2020). Each DATA-waivered practitioner can serve at most 275 patients, making the potential need 10 times higher than the MAT practitioner capacity within the VHA system in Montana. Even if only a fraction of those potentially in need of OUD treatment choose to seek it out, demand could easily exceed the VA's capacity.

The results of this report demonstrate that there is indeed consistent demand for both inpatient substance use treatment and outpatient OUD treatment from veterans, and that the VHA is meeting some, though likely not all, of the demand or need. SOR-funded sites could complement rather than replace existing MAT capacity within the VHA in several ways. Any of these will first require SOR-funded sites to apply to the VHA's community care program and TriWest ${ }^{4}$. It will also be necessary to clarify whether the full set of integrated MAT services, which includes both medication and behavioral therapy, counts as specialty care for the VHA. This distinction is important for determining whether a veteran can seek care outside of the VHA system based on criterion 4 of the MISSON Act (care cannot be furnished within designated access standards by the VHA).

\section{SOR-funded sites can provide additional prescriber capacity.}

If there are veterans waiting to initiate MAT and who cannot because the VHA DATAwaivered practitioners are prescribing at maximum capacity, SOR-funded sites could provide the medication while veterans continue to receive the other behavioral health services that are a part of integrated MAT programs at VHA clinics. Veterans could be approved to seek MAT care outside of the VA system under criterion 4 of the MISSION Act, which allows for specialty care to be provided outside of the system if the wait time within the VHA is more than 28 days. The prescriber capacity present in the SOR-funded sites, as well as the geographic distribution of SOR-funded sites (as shown in Map 1), could be useful for veteran drug courts to draw upon to ensure that veterans can initiate MAT in a timely manner.

\section{SOR-funded sites can fill holes in geographic coverage in southeast Montana.}

Criterion 4 of the MISSION Act states that veterans can seek care outside of the VHA system if access standards are not met, including standards related to travel time to services. For primary care and mental health services, approval to seek care outside of the VHA system can be granted when travel time from a veteran's home to a VHA facility or clinic exceeds 30 minutes. Map 1 shows VHA clinic sites and SOR-funded sites, with a 30-mile buffer around each VHA site (using 30 miles as a proxy for a 30-minute drive). Map 1 clearly shows that SOR-funded sites could provide services to veterans in southeastern Montana, if the behavioral therapy components of MAT are considered mental health care.

${ }^{4}$ For the TriWest application site, see TriWest Healthcare Alliance (2020). 


\section{Map 1. Distribution of SOR and VHA sites across the state with 30-mile buffer around VHA sites}

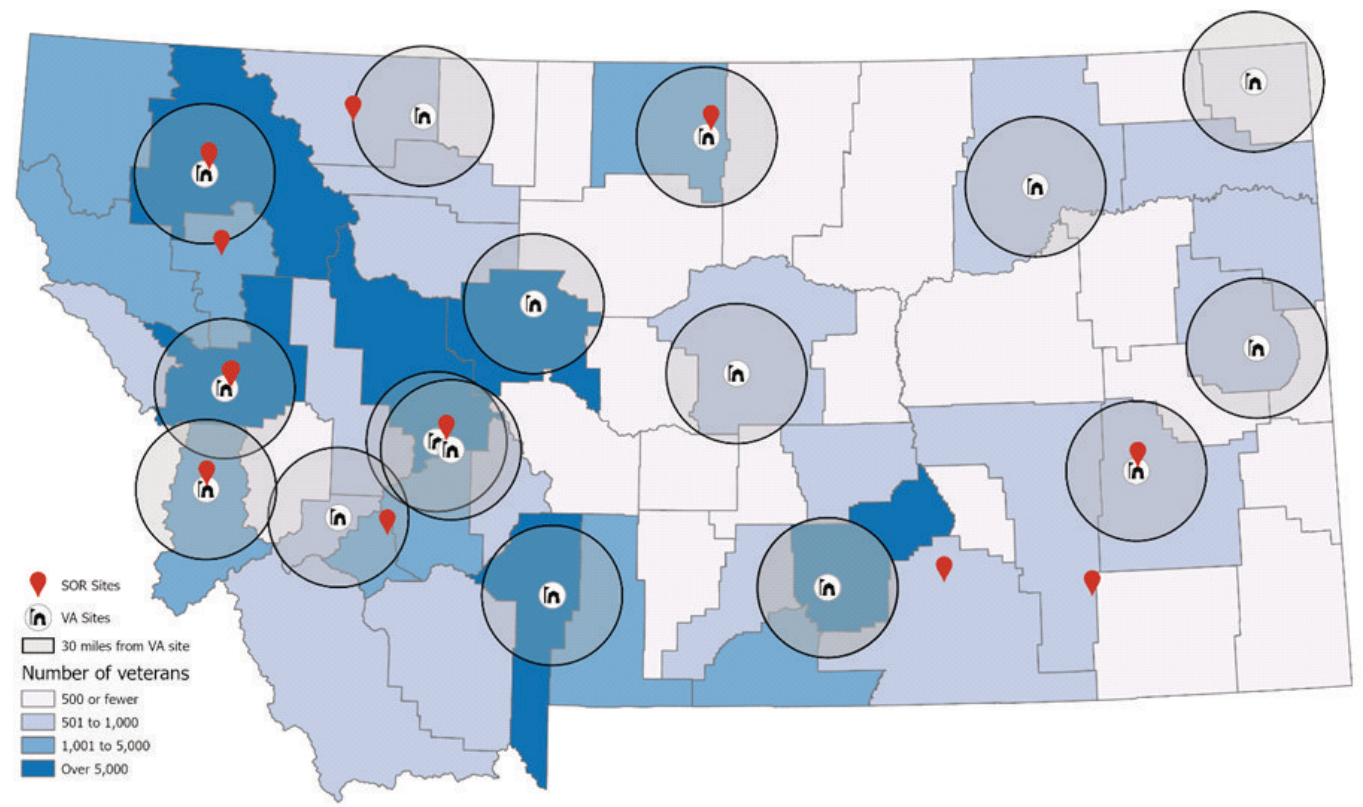

Map 2 shows a 60-mile buffer around each VHA site (using 60 miles as a proxy for a 60minute drive). This map highlights the relatively complete coverage provided by the VHA in terms of geographic access if all MAT services are considered specialty care, although veterans in the southeast corner of Montana could still have increased access at the SORfunded site. Map 2 highlights the need for more innovative collaboration between the VHA and non-VA providers as a way to address both prescriber capacity and geographic access. VHA clinics are well placed around the state and could provide all of the supportive services to veterans receiving MAT from SOR-funded DATA-waivered practitioners.

Map 2. Distribution of SOR and VHA sites across the state with 60-mile buffer around

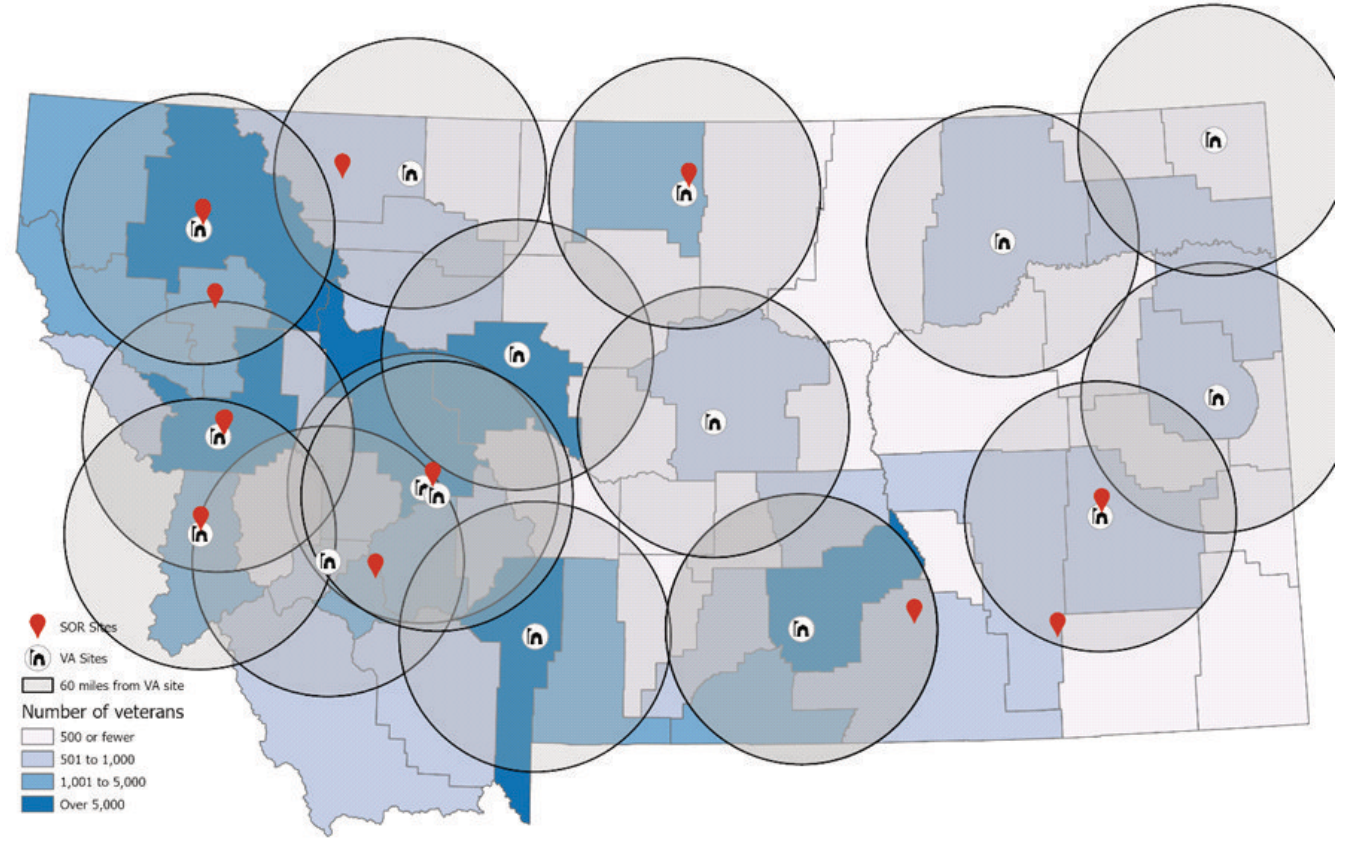




\section{SOR-funded sites can raise awareness of non-VHA MAT programs.}

SOR-funded sites can work with the Montana VHA to raise awareness of prescriber and geographic capacity coverage and limitations for OUD treatment within the VHA system. Specifically, SOR-funded sites can collaborate with Montana Joining Community Forces to bolster outreach opportunities and educate local community organizations serving veterans about SOR programs. The VHA could educate VA schedulers and consult staff that SOR sites exist and could be a resource for both honorably and dishonorably discharged veterans. Finally, SOR-funded sites can engage organizations serving veterans in the community to provide accurate and detailed information about how veterans can be approved to initiate MAT outside of the VHA system. 


\section{REFERENCES}

Bohnert, A. S., IIgen, M.A., Galea, S., McCarthy, J. F., \& Blow, F. (2011). Accidental poisoning mortality among patients in the Department of Veterans Affairs Health System. Medical Care 49(4): 393-396.

Gordon, A.J., Trafton, J.A., Saxon, A.J., Gifford, A.L., Goodman, F., Calabrese, V.S., McNicholas, L., \& Liberto, J. (2007). Implementation of buprenorphine in the Veterans Health Administration: Results of the first 3 years. Drug and Alcohol Dependence 90(2-3): 292-296.

Gordon, Adam, J., Karen Drexler, Eric J. Hawkins, Jennifer Burden, Nodira K. Codell, Amy Mhatre-Owens, Matthew T. Dungan \& Hildi Hagedorn (2020) Stepped Care for Opioid Use Disorder Train the Trainer (SCOUTT) initiative: Expanding access to medication treatment for opioid use disorder within Veterans Health Administration facilities, Substance Abuse, 41:3, 275-282, DOI: 10.1080/08897077.2020.1787299

Montana DPHHS (Department of Public Health and Human Services). (2020). Southwest Montana Veterans Home. https://dphhs.mt.gov/sltc/homelivingoptions/ montanaveteranshomes/swmvh.

QSR International Pty Ltd. (2020). NVivo (released in March 2020). https:// www.qsrinternational.com/nvivo-qualitative-data-analysis-software/home.

SAMHSA (Substance Abuse and Mental Health Services Administration). (2018). 2018 National Survey on Drug Use and Health: Veterans. Report from the Substance Abuse and Mental Health Services Administration. Washington, DC: US Department of Health and Human Services. https://www.samhsa.gov/data/sites/default/files/reports/ rpt23251/6_Veteran_2020_01_14_508.pdf.

TriWest Health Care Alliance. (2020). TriWest Community Care Network. https:// ccn.triwest.com/Forms/AddProvider.aspx.

US Department of Veterans Affairs. (2020). Opioid Safety Initiative (OSI). https:// www.va.gov/painmanagement/opioid_safety_initiative_osi.asp.

US Government Accountability Office. (2019). Veterans health care: Services for substance use disorders, and efforts to address access issues in rural areas. Publication No. GAO-20-35. https://www.gao.gov/assets/710/702940.pdf.

VA MISSION Act. Public Law No. 115-182. S. 2372 -115th Congress (2018).

Vespa, J.E. (2020). Those who served: America's veterans from World War II to the War on Terror. American Community Survey Report ACS-43. US Census Bureau. https:// www.census.gov/content/dam/Census/library/publications/2020/demo/acs-43.pdf. 


\section{CONTACT INFORMATION}

\section{Matthew R. Filteau}

matthew@jgresearch.org

Kristal Jones

kristal@jgresearch.org

Brandn Green

brandn@jgresearch.org 